of no great concern. A conference of meteorologists held in Exeter, UK, in February (www.stabilisation2005.com) disagreed, concluding that such an outcome would be unacceptable to most societies if they had a choice in the matter. Boia himself points out that such a rise in temperature will lead to the loss of mountain glaciers and the destruction of millions of species of plants and animals. He makes a technical error, however, in stating that the reduction of emissions needed to mitigate this rise can be provided solely by the more economical and efficient use of transport. These steps, although necessary, are insufficient: the excessive use of energy for heating and cooling buildings, which in most countries gives rise to $50 \%$ of emissions, also needs to be curbed.

Lomborg is correct that the local environment and living standards are improving for many people. But some climate models would see people reduced to communities perched on hilltops in a depleted natural environment. Some of us might be living on the water in the next generation of ark, indeed the Netherlands is planning to develop floating houses for use in the most flood-prone areas of the country.

An alternative reading of history might conclude that human societies can rise to extraordinary challenges, as the 3,000-year-old society of China surely demonstrates, and should therefore be able to avert the climatic consequences of our actions and prevent their worst effects. Unfortunately that is not the message of this important book.

Julian Hunt is in the Centre for Polar Observation

and Modelling, Department of Space and

Climate Physics, University College London,

Gower Street, London WC1E 6BT, UK.

\title{
Early views of viewing
}

\section{The Moving Tablet of the Eye: The Origins of Modern Eye Movement Research by Nicholas J. Wade \& Benjamin W. Tatler Oxford University Press: 2005. 312 pp. €75, \$145 (hbk); £29,95 (pbk)}

\section{John M. Findlay}

"Why is it to those who are very drunk everything appears to revolve?" Nicholas Wade and Benjamin Tatler use this question, once posed by Aristotle, to illustrate visual vertigo, the illusory motion of the visual world. A further challenging question is why, during our more sober moments, do we not have such experiences, and instead perceive a stable world, despite the continual changes of retinal stimulation resulting from the motion of our eyes.

Since at least the time of Johannes Kepler, some 400 years ago, research in vision has been based on the image-forming eye. The apparent close correspondence between our perceptual experience and our retinal image has generally led to the second question being answered in terms of the 'suppression' of, and 'compensation' for, the changes caused by the eyes' motion. Yet these terms, particularly the latter, presuppose some form of 'inner screen' representation. As the authors point out, the intuitively appealing idea of a detailed mental copy of our visual environment is increasingly recognized as a 'grand illusion'. Some researchers, notably J. Kevin O’Regan and Alva Noë, even reject any form of internalized visual representation. In line with this reappraisal there has been more appreciation of the importance of the mobility of the eyes in visual science; Wade and Tatler at one point contend that "eye movements lie at the heart of contemporary studies of vision".

The Moving Tablet of the Eye is a chronicle of the history, reinterpreted by modern thinking, of studies of seeing actively and of the many contributions to the field from the ancient Greeks to the early twentieth century. One of its idiosyncrasies is the predilection for providing physiognomic rather than geographic information about the scientists involved. The book contains more than sixty miniature

\section{IMAGE \\ UNAVAILABLE FOR COPYRIGHT REASONS}

We normally perceive a stable world even though our eyes keep moving.

credited with both, thanks to a careless attribution in Edmund Huey's classic text on reading. The term saccade was first used in an oculomotor context in Javal's writings in 1879 , but in a footnote describing an observation by A. Lamare, a co-worker in Javal's laboratory at the Sorbonne. Using a mechano-acoustic transducer, Lamare heard noises corresponding to the discontinuous movements of the eyes during reading, and observed that the number of saccades

portraits, but biographic information other than dates is provided only for the major players, such as William Porterfield, Charles Wells, Émile Javal and Raymond Dodge.

The first two names highlight the advanced level of intellectual activity in Scotland in the eighteenth and early nineteenth centuries. Porterfield, an Edinburgh physician, certainly appreciated the importance of eye movements. In a publication in 1737 he decried the "Vulgar Error" of assuming that we see everything distinctly, clearly and at the same time. Wells, who was educated in Scotland but worked in London, demonstrated (using extended vestibular stimulation, rather than inebriation) that visual vertigo is linked to eye motion. His use in the 1790s of after-images for this purpose anticipated the major technique used to study eye movements during the following century. Wells successfully defended his position against a challenge from the august figure of Erasmus Darwin, whose integration of speculative science and ponderous poetry is well represented in the book and provided the inspiration for the title.

Another notable piece of historical research by the authors reveals the initial use of the term 'saccade' and the first appreciation of the jerky quality of eye scanning. Javal, a distinguished French ophthalmologist, is now often per line of text is unchanged, regardless of the viewing distance. However, he didn't get round to publishing until 1892. In fact, no less a figure than Ewald Hering carried out a similar experiment, correlated the resultant "dull clapping" sounds with after-image movements, and published the finding, also in 1879.

This book is extensive and thorough but not exhaustive. The history largely stops in the early years of the twentieth century, so the near absence of any oculomotor neuroscience is justifiable - although the fascinating neurological condition of 'psychic paralysis of gaze' might have merited a mention. Another surprising omission is the work of E. E. Maddox on the preconditions for vergence movement. The authors have made every effort to integrate the study of looking with that of seeing, but the malign influence of the grand illusion can perhaps still be detected when we read that the saccade-and-fixate strategy "evolved as an adaptation to the demands of a highly mobile eye". But these are minor blemishes on a fascinating work and a splendid scholarly achievement. The book will surely stand as the definitive text on the history of eye-movement research for many years to come. John M. Findlay is in the Department of Psychology, University of Durham, South Road, Durham DH1 3LE, UK. 